\title{
EXPERIMENTAL PRODUCTION OF CLINICAL TYPES OF SYPHILIS IN THE RABBIT *
}

\author{
WADE H. BROWN, M.D., AND LOUISE PEARCE, M.D. \\ NEW YORK
}

Syphilis in the human subject is characterized by the occurrence of a succession of lesions of various types which follow one another in a more or less orderly progression from the chancre to the terminal stages of the infection, and while to each period of the infection certain types of lesions have been assigned, the order of their appearance is not entirely fixed nor can one say just what lesions may be expected to occur in a given case.

The factors that determine these features of the disease may be numerous, and the results of their action differ so widely that diversity rather than uniformity has come to be recognized as one of the most fundamental characteristics of syphilis. The causes which underly this diversity of clinical types are but little understood. It is of course obvious that there are two sets of factors which may contribute to this condition, namely, the reactive mechanism of the host and the disease producing properties of the organisms concerned.

Within recent years, the tendency has been to lay more and more stress on the influence of the latter group of conditions. The possibilities of the existence of so-called strains of Spirochaeta pallida was first suggested by Noguchi ${ }^{2}$ and later made the subject of experimental investigations by Nichols, ${ }^{2}$ Reasoner ${ }^{3}$ and others. More recently this idea has been emphasized by the work of Levaditi, Marie ${ }^{4}$ and their co-workers in connection with general paresis. As yet, however, the subject of the cause of clinical variation is an open one, and while syphilographers have recognized the fact that many peculiarities of the infection may be due to causes other than strain differences, this possibility has been more or less neglected by experimental investigators.

It is not easy to approach the problem of clinical variation by means of observation on the human subject, since such a small part of the phenomena of infection can be observed in an individual case, and neither the host nor the causative agent is subject to the necessary

\footnotetext{
* From the Laboratories of the Rockefeller Institute for Medical Research, New York.

1. Noguchi: J. Exper. Med. 15:201, 1912.

2. Nichols: J. Exper. Med. 19:362, 1914.

3. Reasoner: J. A. M. A. 67:1799, 1916.

4. Levaditi and Marie: Ann. Int. Past. 33:741, 1919. Marie, Levaditi and Banu: Compt. rend. Acad. d. Sc. 170:1021, 1920.
} 
measure of control. In the experimental animal, however, a large part of these difficulties are removable, and it is possible to reproduce many of the phenomena of the human infection under conditions of acceptable control. Thus by local inoculation into the testicles or scrotum of the rabbit, one may obtain an infection which begins with a primary lesion and after a lapse of from six to twelve weeks, is marked by the appearance of a variety of lesions in other parts of the body, together with a general lymphadenitis and at times by constitutional disturbances; there are lesions of the skin and appendages, the mucous membranes, the periosteum and bones, and of the eyes. The infection is not identical with that in man but the analogy is sufficiently close for one to make comparisons, and, at the same time, the differences are sufficiently great to enable one to make clear-cut experimental distinctions.

Variation in the clinical course of the disease is characteristic of the animal, as it is of the human, infection, and there are, as we have said, two aspects of the problem of variation, only one of which has been dealt with from an experimental standpoint. The subject of variation is an intricate one and at this time we do not propose to consider the ultimate possibilities of either of the potential factors concerned.

It has been noted, however, that with the use of a given strain of Spirochaeta pallida, one may still obtain infections which exhibit decided clinical variations, not only in the type of lesions which appeared in a given group of tissues, but equally so in the groups of tissues involved and this is of more fundamental importance. An analysis of the circumstances under which such variations occurred showed an appreciable connection between the experimental conditions employed and the type of infection produced. This was especially noticeable in the frequency with which keratitis and iritis occurred following the use of one set of conditions and the frequency with which lesions of the periosteum and bone followed another.

Previous experiments had shown that, while generalized lesions occurred in only a small percentage of rabbits inoculated by certain methods, it was possible to modify the course of the infection to such an extent that the occurrence of generalized lesions became the rule rather than the exception." This work was founded on a modified conception of the theory of inhibition. That the development of a lesion in one testicle was capable of inhibiting the development of other lesions in the rabbit was first demonstrated by Nichols ${ }^{6}$ in connection with metastatic lesions of the testicles and applied by him in

5. Brown and Pearce: Arch. Dermat. \& Syph., 1920, 11:675.

6. Nichols, H. J. : J. Exper. Med. 14:211, 1911. 
an explanation of the phenomena of relapse in human syphilis with especial reference to neurorecidives. ${ }^{\top}$

Realizing the importance of the influence which the primary reaction exerted on the character of the infection in the rabbit, we were first able to convert a local into a general disease by diminishing or suppressing the testicular reaction. With a knowledge of what had been accomplished in this respect, it appeared that one might go a step further and, by modifying the defensive reaction in different ways, produce types of disease that would conform to alterations in the mechanism of animal resistance, the infecting organism being maintained as a constant factor in the reaction.

\section{EXPERIMENTAL MODIFICATION OF THE INFECTION}

Experiments that have been carried out show that definite type alterations can be produced in response to the use of experimental procedures which influence the reaction to infection. The character of the changes and the manner in which they were obtained may be illustrated by the following experiment:

Forty-four rabbits were inoculated in the testicles with the Nichols strain of Spirochaeta pallida, using for each testicle 0.5 c.c. of an emulsion containing numerous spirochetes, as many as four to eight to the microscopic field. The animals were divided equally into two series, A and B. Those of Series A were inoculated in both testicles and those of Series B in only one testicle. Lesions were palpable in the testicles at from ten to fourteen days after inoculation. Each series was then further divided into four groups, making each group as nearly comparable to the others of the series as possible from the standpoint of the animals and the state of the testicular infection. The several groups were handled as follows:

Group 1; Controls; Six Animals.-The infection in this group of animals was permitted to progress without interference of any kind.

Group 2; Early Castration; Five Animals.-These animals were castrated fourteen days after inoculation. In Series $A$, both testicles were removed; in Series B, only the infected testicle was removed.

Group 3; Late Castration; Five Animals.-Castration was carried out as in Group 2, twenty-eight days after inoculaton.

Group 4; Therapeutic Suppression of Testicular Reaction; Six Animals.These animals were given a single intravenous injection of arsenophenylglycyl dichloro-m-aminophenol for the purpose of temporarily suppressing the reaction in the testicle and of lowering the animal resistance.

All animals were kept under observation for from three to three and a half months after inoculation. During this time, they were examined almost daily and full records of the progress of the infection were kept.

7. Nichols, H. J.: J. A. M. A. 63:466, 1914.

8. All operations were done under ether anesthesia. 
The purpose of some of these procedures may require a brief explanation. Early castration was employed as a means of aborting the testicular reaction early in the course of the infection and thus shifting the defensive reaction to other tissues before any considerable degree of protection had been developed. The use of late castration, on the other hand, represented an attempt to permit the infection to progress to a point at which the protection developing from the primary foci was nearly, but not quite, sufficient to prevent the occurrence of lesions in other parts of the body. The success of this attempt hinged on the judgment of the proper time at which to intervene, and castration was performed as the first cycle of testicular reaction was nearing completion. The progress of the infection was, of course, not uniform in all animals, and the time fixed for castration was based on the average animal of the group; this was too early in some cases and too late in others, but such irregularities could not be avoided if a constant time element were to be maintained.

The use of a therapeutic agent in this series of experiments was intended to accomplish more than a temporary restraint on the primary lesions. The effects produced by such agents are not entirely measurable by the reduction which they produce in existing lesions and, while we cannot discuss the action of therapeutic agents, it is necessary to state that in addition to any effect which may be attributable to a temporary suppression of existing lesions, therapeutic agents frequently nullify any protection that has been developed and render subsequent reactions on the part of the animal less effectual. It was for this purpose that arsenophenylglycyl dichloro-m-aminophenol was used.

The period of observation chosen was fixed with a view to including only one cycle of general reaction. Clinical relapse is prone to occur in the animal as in the human subject, and the inclusion of this class of phenomena would introduce more complex elements, which cannot be considered in this article.

\section{RESULTS OBTAINED}

The influence which these procedures exerted on the course and character of the infection may be learned from a comparison of the case incidence and relative severity of generalized lesions, the groups of tissues involved, the order of involvement and the time after inoculation at which the lesions appeared. For convenience, these facts have been tabulated in parallel columns in the table. The list of conditions given includes no lesions of uncertain or doubtful character. When any doubt existed, the condition was recorded as suspicious or doubtful, as the case might be, and animals showing such affections are marked with an asterisk (*). 
As one examines the data recorded in the table, the first thing to be noted is that the occurrence and the severity of generalized lesions among animals of a given group was inconstant. This indicates the existence of a variable in the reaction of individual animals to a given set of conditions which must be regarded as present in all cases.

Effect Produced on the Character of the Infection by Modifying the Reaction of the Host in Animals Inoculated with a Constant Dose of a Given Strain of Spirochaeta Pallida

\begin{tabular}{|c|c|c|c|c|c|}
\hline \multicolumn{3}{|c|}{ Series A: Bilateral Inoculations } & \multicolumn{3}{|c|}{ Series B: Unilateral Inoculations } \\
\hline $\begin{array}{l}\text { Number } \\
\text { and } \\
\text { Group }\end{array}$ & $\begin{array}{c}\text { Generalized } \\
\text { Syphills }\end{array}$ & $\begin{array}{l}\text { Lesions in Order of } \\
\text { Their Appearance, } \\
\text { Time in Days }\end{array}$ & $\begin{array}{l}\text { Number } \\
\text { and } \\
\text { Group }\end{array}$ & $\begin{array}{l}\text { Generalized } \\
\text { Syphills }\end{array}$ & $\begin{array}{l}\text { Lesions in Order of } \\
\text { Their Appearance, } \\
\text { Time in Days }\end{array}$ \\
\hline $\begin{array}{c}\text { Group } 1 \mathrm{~A} \\
\mathbf{1} \\
2 \\
3 \\
4 \\
5 \\
6\end{array}$ & $\begin{array}{l}\bar{z}^{*} \\
\bar{z}^{*}\end{array}$ & S.(57) & $\begin{array}{c}\text { Group } 1 \mathrm{~B} \\
1 \\
2 \\
3 \\
4 \\
4 \\
5 \\
6\end{array}$ & $\begin{array}{c}\overline{+}^{*} \\
\dot{+}^{*} \\
++ \\
++++\end{array}$ & $\begin{array}{ll}\text { S. }(57,78) & \text { E. }(78) \\
\text { P.B.(55) } & \text { F. }(78,84) \\
\text { S. }(57,71) & \text { P.B. }(63)\end{array}$ \\
\hline $\begin{array}{c}\text { Group 2A } \\
1 \\
2 \\
3 \\
3 \\
4 \\
5\end{array}$ & $\begin{array}{c}\overrightarrow{+}^{*} \\
\overline{++} \\
+++\end{array}$ & $\begin{array}{l}\text { S.(28) MM.(41) } \\
\text { P.B.(79) S. (89) } \\
\text { P.B.(57,78) S.(79) } \\
\text { E.(85) }\end{array}$ & $\begin{array}{c}\text { Group } 2 B \boldsymbol{t} \\
\mathbf{1} \\
2 \\
3 \\
\mathbf{4}\end{array}$ & $\begin{array}{l}++ \\
++ \\
+ \\
++\end{array}$ & $\begin{array}{l}\text { P.B.(50) } \\
\text { MM.(41) P.B.(73,78) } \\
\text { P.B.(57) } \\
\text { P.B.(41,57) S.(57) }\end{array}$ \\
\hline $\begin{array}{c}\text { Group } 3 \mathrm{~A} \\
1 \\
2 \\
3 \\
\\
\frac{4}{5} \\
\end{array}$ & $\begin{array}{c}++ \\
++ \\
++ \\
++\end{array}$ & $\begin{array}{l}\text { P.B.(57) S.(71) } \\
\text { S.(29) MM. }(63) \\
\text { E.(80,84) } \\
\text { E. }(85) \text { S. }(65)\end{array}$ & $\begin{array}{c}\text { Group } 3 B+ \\
1 \\
2 \\
3 \\
4\end{array}$ & $\begin{array}{c}\frac{+}{++} \\
-^{*}\end{array}$ & $\begin{array}{l}\text { MM.(63) } \\
\text { P.B.(50) S. }(50,76)\end{array}$ \\
\hline $\begin{array}{c}\text { Group } 4 \mathrm{~A} \\
1 \\
2 \\
3 \\
3 \\
4 \\
5 \\
5 \\
6\end{array}$ & $\begin{array}{l}+ \\
+ \\
+ \\
++ \\
++ \\
++\end{array}$ & $\begin{array}{l}\text { P.B.(63) S. }(71,78,80) \\
\text { P.B.(57) } \\
\text { P.B.(50) S. }(50,57) \\
\text { M.M.(71) } \\
\text { P.B.(41) } \\
\text { P.B.(71,78) }\end{array}$ & $\begin{array}{c}\text { Group 4B } \\
1 \\
2 \\
3 \ddagger \\
4 \\
5\end{array}$ & $\begin{array}{c}++ \\
++ \\
+ \\
++ \\
++ \\
++\end{array}$ & $\begin{array}{l}\text { P.B.(55) S.(90) } \\
\text { P.B.(55,57) } \\
\text { P.B.(47) } \\
\text { P.B.(55) E.(97) } \\
\text { S.(35) P.B.(59) } \\
\text { S.(63) MM.(97) }\end{array}$ \\
\hline $\begin{array}{r}-\mathrm{Ne} \\
+\mathrm{Sll} \\
++\mathrm{Mc} \\
\mathrm{E} ., \text { eye } \\
\text { bone; S., } \\
\text { * Anim } \\
+ \text { One } \\
\pm \text { The } \\
\text { and was } \\
\text { There was } \\
\text { Figures }\end{array}$ & $\begin{array}{l}\text { aal in each } \\
\text { nal develop } \\
\text { thetized an } \\
\text { bacterial } \\
\text { parenthese }\end{array}$ & $\begin{array}{l}\text { these groups died } \\
\text { symptoms of acute } \\
\text { killed. Spirochetes } \\
\text { ection. } \\
\text { () give the time in }\end{array}$ & $\begin{array}{l}\text { nite. } \\
\text { fore results } \\
\text { meningitis } \\
\text { were recov }\end{array}$ & $\begin{array}{l}\text { narked infect } \\
\text { mely marked } \\
\text { us borders; }\end{array}$ & $\begin{array}{l}\text { ion } \\
\text { infection } \\
\text { P.B., periosteum and } \\
\text { termined. } \\
\text { lesions were appearing } \\
\text { he cerebrospinal fluid. } \\
\text { appeared. }\end{array}$ \\
\hline
\end{tabular}

Considering the character of the infection which occurred under the several conditions employed, it will be seen that it varied from an infection in which scarcely any lesions were demonstrable (except those in the testicles), as in Group $1 \mathrm{~A}$, to infections in which a variety of generalized lesions occurred in practically all the animals of the group. This is the first respect in which it can be seen that a modification in the type of the infection was produced. 
The next condition to be noted is that the character of the disease among the animals of a given group also varied. In Group $1 \mathrm{~B}$, for example, there was one case of skin and eye infection, another of bone and eye infection and a third of skin and bone infection; or, there were two cases each of skin, bone and eye infection. A similar condition prevailed in Group $2 \mathrm{~A}$ but in $2 \mathrm{~B}$ a different type of result was obtained. Here there was an unbroken series of cases of bone syphilis, two of the four animals showing skin or mucous lesions as well.

That the occurrence of such a group of infections cannot be regarded as a coincidence is shown by the fact that when analogous conditions were employed in Groups $4 \mathrm{~A}$ and $\mathrm{B}$, the same type of infection was again produced. Further than this, a distinctly different type of infection was produced in the animals of Group $3 \mathrm{~A}$ by permitting the testicular reaction to progress much longer before suppression was attempted. In only one of the four animals in this group did bone lesions occur as contrasted with its occurrence in all of those of Groups $2 \mathrm{~B}$ and $4 \mathrm{~A}$, and five of the six animals in $4 \mathrm{~B}$. The infection in Group $3 \mathrm{~A}$ was preeminently one of skin and eyes; three of the animals showed skin lesions and three of them eye lesions and in one the eye lesions were the only lesions present.

The prominence of the latter type of infection is not fully brought out in this series of experiments, which covered only a little more than three months. This, as we realized, did not afford a proper opportunity for the development of eye lesions, which are rarely seen until toward the end of the third month and which tend to occur later when other conditions are most marked. Skin lesions showed the same tendency to late appearance under similar circumstances, and late lesions would doubtless have been more numerous had the period of observation been longer. The occurrence of these late lesions would not have altered the general type of the infection, however, but would merely have served to emphasize the conditions described.

In contrasting the manifestations of syphilis in the rabbit with those of man, attention should be called to two conditions: First, that the disease in the rabbit is not entirely comparable either to the acquired or the congenital form of the human infection, but presents an interesting combination of the two conditions. In the second place, the most noticeable difference in the sequence of tissue involvement is the position occupied by skin and bone infections, which is the reverse of that in man (acquired syphilis). This is to be accounted for by the fact that in the rabbit the skin is a furred coat, and for the most part, is less subject to infection or to the action of a host of conditions which predispose to skin infection than is the skin of man. 


\section{CLINICAL TYPES OF DISEASE}

The fact that it is possible to produce a scale of variations in the clinical course of syphilitic infections by modifying the reaction of the experimental animal, indicates the importance of this group of factors in determining the character of the disease. It also suggests that each group of tissue reactions, or lesions, bears some relation to the reactions or lesions of other tissues and, therefore, to the course of the disease as a whole.

We shall not attempt to give a detailed statement of these relationships, but the simplest explanation which can be offered for the results reported is one which is based on inherent tissue susceptibility and tissue reactivity.

In the first place, the occurrence or nonoccurrence of generalized lesions in the rabbit, as well as the character of these lesions, appears to depend primarily on a protective reaction which takes place at the primary foci of infection and to some extent on the relative susceptibility of other tissues. It is difficult to say what part the latter condition plays in determining the general course of the disease, but unless a given tissue furnishes suitable conditions for the growth and multiplication of the spirochetes, no very active lesions are likely to occur, nor will the reaction in such tissues contribute materially to the defensive mechanism either locally or generally.

In the second place, it is conceivable that the protection developed from a given source may not affect all tissues, or even all parts of the body, in an equal degree or at the same rate, but that it may be extended progressively from the primary lesions to successive tissue groups, being sufficient to protect one group of tissues at a time when little or no protection is afforded to another.

According to this conception, the tissues which become involved or the lesions which develop in any given case would represent a measure of the effectiveness and the state or progress of the reaction in that animal. That such may be the case is indicated by the fact that certain groups of tissues tend to become involved in a given order; thus, bone lesions, if they occur at all, tend to follow those of the testicles or scrotum, while keratitis and iritis occur toward the end of the cycle of tissue involvement, the skin and mucous membranes occupying an intermediate position. Further than this, it has been shown that by early and radical interference, it is possible to so alter the course of the disease as to cause bone lesions practically to supplant those of the testicle in the defensive reaction; conversely, by permitting the testicular reaction to progress to a given point, it is possible to confer protection on this group of structures. In this case no bone lesions occur, but the generalized disease begins with involvement of the next group of tissues in order, producing an infection which is essentially one of the skin, mucous membranes and eyes. 
Going still further, it is found that while, in the majority of animals inoculated in both testicles a high degree of protection seems to be conferred on other tissues of the body, in many instances, the protection fails to reach the eyes, lesions of the cornea and iris appear as the only clinical manifestations of a generalized disease.

This fact, taken in conjunction with other circumstances surrounding eye infections, is of especial interest on account of a point of view which is introduced toward certain manifestations of syphilis, especially neurosyphilis. In the rabbit, eye lesions are not only terminal and frequently the only generalized conditions that occur, but they are also relatively slight and more prone to repeated relapse than any other class of lesions. In the light of the conditions reported in the foregoing, these circumstances suggest that all tissues are not equally protected by the general reaction which occurs during the early stages of a syphilitic infection and that certain tissues which fail to receive this protection, although less susceptible to injury or infection than other tissues, may be capable of only a relatively slight degree of self-protection. This is undoubtedly the case in the experimental animal, and if similar conditions obtain in man, such conditions as neurosyphilis may be explainable on this basis.

It was the peculiar chain of circumstances surrounding eye infections which first drew our attention to the possibilty of establishing the existence of a definite sequence of defensive reactions in the experimental animal with its corollary of a sequence in tissue protection and the possibility of producing infections of different types by modifying the defensive reaction at its source. The type of infection produced, therefore, by the inoculation of a given strain of Spirochaeta pallida, may be regarded as a resultant of the operation of the several factors indicated and subject, through this cause alone, to a wide degree of variation.

\section{SUMMARY AND CONCLUSIONS}

In the course of investigations dealing with generalized syphilis in the rabbit, it was noted that distinctly different types of disease were frequently produced by inoculations made with a given strain of Spirochaeta pallida; it also appeared that there was an appreciable connection between the experimental conditions employed and the type of disease which occurred.

Since it had been found possible to convert a disease which is usually localized into a generalized disease by diminishing or suppressing the primary reaction, it appeared that by modiying the reaction in different ways, one might produce types of disease which would conform to alterations in the defensive mechanism. Experiments carried out on a large series of animals showed that such was the case. By various 
experimental procedures, different types of infection were produced, and in this way it was found that there was a definite sequence of tissue involvement or of tissue reactions which made it possible to produce infection or to confer protection on a given group of tissues according to the nature of the means employed.

From the manner in which the infection responded to modifications of the defensive reaction, the conclusion was drawn that a wide variation in the clinical type of the disease might be traceable to this one group of causes. This, of course, does not eliminate the possibilty that variation in the biologic properties of the infecting organisms may contribute to further variations in the type of the disease. 